\title{
Prenatal levonorgestrel exposure induces autism-like behavior in offspring through $E R \beta$ suppression in the amygdala
}

Yuanlin Zou ${ }^{1,2 \dagger}$, Qiaomei Lu ${ }^{1,2+}$, Dan Zheng ${ }^{3 \dagger}$, Zhigang Chu ${ }^{4}$, Zhaoyu Liu ${ }^{1,2}$, Haijia Chen ${ }^{5}$, Qiongfang Ruan ${ }^{4}$, Xiaohu Ge ${ }^{5}$, Ziyun Zhang ${ }^{1,2}$, Xiaoyan Wang ${ }^{5}$, Wenting Lou' ${ }^{4}$, Yongjian Huang ${ }^{2}$, Yifei Wang ${ }^{5}$, Xiaodong Huang ${ }^{4}$, Zhengxiang Liu ${ }^{1,2}$, Weiguo Xie ${ }^{4^{*}}$, Yikai Zhou ${ }^{3^{*}}$ and Paul Yao ${ }^{1,2,4^{*}}$ (i)

\begin{abstract}
Background: Autism spectrum disorder (ASD) is characterized by impairments in social communication and restricted or repetitive behaviors or interests. ASD is now diagnosed in more than one out of 100 children and is biased towards males by a ratio of at least 4:1. Many possible explanations and potential causative factors have been reported, such as genetics, sex, and environmental factors, although the detailed mechanisms of ASD remain unclear.

Methods: The dams were exposed through oral contraceptives to either vehicle control (VEH) alone, levonorgestrel (LNG) alone, ethinyl estradiol (EE) alone, or a combination of $L N G / E E$ for 21 days during their pregnancy. The subsequent 10-week-old offspring were used for autism-like behavior testing, and the limbic tissues were isolated for analysis. In another experimental group, 8-week-old male offspring were treated by infusion of ER $\beta$ overexpression/knockdown lentivirus in the amygdala, and the offspring were analyzed after 2 weeks.

Results: We show that prenatal exposure of either LNG alone or a LNG/EE combination, but not EE alone, results in suppression of ER $\beta$ (estrogen receptor $\beta$ ) and its target genes in the amygdala with autism-like behavior in male offspring, while there is a much smaller effect on female offspring. However, we find that there is no effect on the hippocampus and hypothalamus. Further investigation shows that ERß suppression is due to LNG-mediated altered methylation on the ERß promoter and results in tissue damage with oxidative stress and the dysfunction of mitochondria and fatty acid metabolism, which subsequently triggers autism-like behavior. Overexpression of ERß in the amygdala completely restores LNG-induced ER $\beta$ suppression and autism-like behaviors in offspring, while ER $\beta$ knockdown mimics this effect, indicating that ERß expression in the amygdala plays an important role in autism-like behavior development.

Conclusions: We conclude that prenatal levonorgestrel exposure induces autism-like behavior in offspring through ER $\beta$ suppression in the amygdala. To our knowledge, this is the first time the potential effect of oral contraceptives on the contribution of autism-like behavior in offspring has been discovered.
\end{abstract}

Keywords: Amygdala, Autism-like behavior, Estrogen receptor $\beta$, Oral contraceptives, Oxidative stress

\footnotetext{
*Correspondence: wgxie@hotmail.com; zhouyk@mails.tjmu.edu.cn;

vasilis112@yahoo.com

${ }^{\dagger}$ Equal contributors

${ }^{4}$ Institute of Burns, Tongren Hospital of Wuhan University, Wuhan 430060,

People's Republic of China

${ }^{3}$ Institute of Environmental Medicine, Tongji Medical College, Huazhong

University of Science and Technology, Wuhan 430030, People's Republic of

China

${ }^{1}$ Internal Medicine of Tongji Hospital, Tongji Medical College, Huazhong

University of Science and Technology, Wuhan 430030, People's Republic of

China

Full list of author information is available at the end of the article
} 


\section{Background}

Autism spectrum disorder (ASD) is characterized by impairments in social communication and restricted or repetitive behaviors or interests [1]. ASD is now diagnosed in more than one out of 100 children [2]. The identified prevalence of ASD has increased in a short period of time with an epidemic proportion in the world. The detailed mechanism of ASD remains unclear [3], and many possible explanations and potential causative factors have been reported. A three-hit theory, which includes the combination of genetic/epigenetic, environmental, and sex factors for the mechanism of ASD, has been widely accepted [4]. Interestingly, ASD is biased towards males by a ratio of at least 4:1, suggesting that fetal or perinatal exposure to elevated male hormones may increase susceptibility towards autism [5-7]. On the other hand, there is a hypothesis that estrogen, especially ethinyl estradiol (EE) from COC (combined oral contraceptives), may play a role in ASD development [8], although current literatures have not reached a conclusion [9].

$\operatorname{ER} \beta$ (estrogen receptor $\beta$ ) is the principal estrogen receptor expressed in brain areas $[3,10,11]$. An earlier study has found a significant association of the ER $\beta$ gene with scores on the Autism Spectrum Quotient and the Empathy Quotient in ASD subjects, and in the ER $\beta$ gene, the $C$ allele in rs1271572 and rs1152582 were associated with higher AQ in the typical population and were also found to be more frequent in cases than in controls [12]. Moreover, ER $\beta$ mediates some of the effects on anxiety, locomotor activity, fear responses, and learning behavior in mice [13]. It has been recently reported that the ER $\beta$ expression in the middle frontal gyrus of ASD subjects is decreased, indicating that ER $\beta$ expression in the brain may play a role in the development of ASD [14].

We have previously reported that ER $\beta$ is responsible for the basal expression of superoxide dismutase (SOD2) [15] and estrogen-related receptor $\alpha(E R R \alpha)$ [16], where ERR $\alpha$ expression regulates mitochondrial function and fatty acid metabolism and SOD2 regulates oxidative stress $[17,18]$. Therefore, ER $\beta$ suppression may bring potential damage and disorders to the brain tissues through SOD2 suppression-mediated oxidative stress and DNA break as well as ERR $\alpha$ suppression-mediated dysfunction of mitochondria and fatty acid metabolism.

Oral contraceptive hormones, including EE and levonorgestrel (LNG), have been the mainstay contraceptive hormones for the last four decades and have potential effects on behavior and the central nervous system [19]. We hypothesize that prenatal exposure of oral contraceptive hormones may contribute to ASD development in offspring. Previous studies demonstrate that $10 \mu \mathrm{g} /$ $\mathrm{rat} /$ day EE and $20 \mu \mathrm{g} / \mathrm{rat} /$ day LNG are the lowest individual doses found to inhibit ovulation in intact rodents
[20-23]. In order to find the best dose for the treatment of our dams, we tried two combination doses, with the low dose of $10 \mu \mathrm{g} E \mathrm{E} / 20 \mu \mathrm{g}$ LNG and high dose of $30 \mu \mathrm{g}$ EE/60 $\mu \mathrm{g}$ LNG per rat each day, as recommended by a recent study [19]. Our preliminary data showed that high doses brought many problems to the dams, including abnormal pregnancy, such as bleeding, or, in some case, the pregnancy was prevented or interrupted even though a vaginal plug was found after mating. Therefore, we chose the dosage of $10 \mu \mathrm{gEE} / 20 \mu \mathrm{g}$ to be the final treatment for the dams.

In this study, we show that prenatal exposure of either LNG alone or combined LNG/EE treatment induces significant ER $\beta$ suppression in the amygdala and autismlike behavior in offspring, while EE2 treatment alone shows no effect. Further investigation shows that ER $\beta$ suppression is due to LNG-mediated altered methylation on the ER $\beta$ promoter. Overexpression of ER $\beta$ in the amygdala completely restores LNG-mediated autism-like behavior in offspring, while ER $\beta$ knockdown mimics this effect. This suggests that prenatal LNG exposure may play a dominant role in oral contraceptive-mediated autism-like behavior through ER $\beta$ suppression in the amygdala.

\section{Methods \\ Materials}

The antibodies for ERR $\alpha$ (ab37438), H2AX (ab20669) and $\gamma \mathrm{H} 2 \mathrm{AX}$ (ab2893), H3K9me2 (ab1220), and H3K9me3 (ab8898) and H3K27me3 (ab6002) were obtained from Abcam. Antibodies for $\beta$-actin (sc-47,778), ER $\beta$ (sc$137,381)$, and SOD2 (sc-30,080) were obtained from Santa Cruz Biotechnology. LNG and EE were obtained from Sigma. 3-Nitrotyrosine (3-NT) was measured using the 3Nitrotyrosine ELISA Kit (ab116691 from Abcam) per manufacturers' instructions. The mitochondrial fraction was isolated using a Pierce Mitochondria Isolation Kit (Pierce Biotechnology) per manufacturers' instructions. Nuclear extracts were prepared using the NE-PER Nuclear and Cytoplasmic Extraction Reagents Kit (Pierce Biotechnology). Protein concentration was measured using the Coomassie Protein Assay Kit (Pierce Biotechnology).

\section{Generation of lentivirus}

Rat ER $\beta$ expression lentivirus. The rat complementary DNA (cDNA) for ER $\beta$ was obtained from Open Biosystems. The cDNA for rat ER $\beta$ was subcloned into the pLVX-Puro vector (from Clontech) with the restriction sites of Xho1 and Xba1 using the below primers: ER $\beta$ forward primer: $5^{\prime}$-gtac-ctcgag-atg aca ttc tac agtcctgct-3' (Xho1) and ER $\beta$ reverse primer: 5'-gtac-tctaga-tcactg agactg tag gttctg-3' (Xba1). The ER $\beta$ or empty control (CTL) was expressed through Lenti- $\mathrm{X}^{\mathrm{m}}$ Lentiviral 
Expression Systems (from Clontech) per manufacturers' instructions.

Rat ER $\beta$ shRNA lentivirus. According to our preliminary data from in vitro cell culture experiments, the following sequence was confirmed as the most effective in knockdown rat ERß: 5'-GGT CAT GTG AAG GAT GTA AGG-3'. The shRNA template for ER $\beta$ or scrambled was designed (sense strand + loop + antisense strand), and the related double strand DNA (dsDNA) was synthesized and annealed. They were then inserted into the pLVX-shRNA1 vector (from Clontech) using BamH1/EcoR1 restriction sites. The Scrambled (CTL) or $\operatorname{shER} \beta$ lentivirus was then expressed through Lenti- $\mathrm{X}^{\mathrm{n}}$ shRNA Expression Systems (from Clontech) per manufacturers' instructions.

\section{In vivo rat experiments}

Sprague-Dawley rats (Wuhan, China) were maintained under standard 12-h light/dark cycles and given ad libitum access to food and water. The animal protocol conformed to the US NIH guidelines (Guide for the Care and Use of Laboratory Animals, No. 85-23, revised 1996) and was reviewed and approved by the Institutional Animal Care and Use Committee from Tongji Medical College and Wuhan University.

\section{Rat protocol 1}

Adult (3 months old) female Sprague-Dawley rats were monitored for estrous cycles with daily vaginal smears. Only rats with at least two regular 4- to 5-day estrous cycles were included in the studies. The females were caged with proven males, and pregnancy was verified by observation of a sperm plug, which was designated as day 0 of pregnancy. Dams were randomly assigned to the following drug conditions: LNG $(20 \mu \mathrm{g}$ levonorgestrel), EE $(10 \mu \mathrm{g}$ ethinyl estradiol), or LNG/EE $(20 \mu \mathrm{g}$ LNG and $10 \mu \mathrm{g}$ EE combination), and VEH rats received the same volume of vehicle. Drugs were suspended in $5 \%$ ethanol in organic sesame oil, and $0.1 \mathrm{ml}$ were given daily through subcutaneous injection at the nape starting from day 1 until pup delivery for $\sim 21$ days. The same individuals handled the rats for injections, and experimenters were naive to drug conditions. The male and female offspring were separated from the dams on day 21 and fed until 9-10 weeks old for further experiments. Parts of 9- to 10-week-old offspring were then used for behavior tests, including autism-like and anxiety-like behavior testing. After that, the offspring were sacrificed, and the different brain tissues, including the amygdala, hypothalamus, and hippocampus, were isolated, flash frozen in dry ice, and then stored in a $-80{ }^{\circ} \mathrm{C}$ freezer for the analysis of gene expression, SOD2 activity, superoxide anion release, DNA damage, mitochondrial function, and fatty acid metabolism. In addition, other parts of the offspring were used for the isolation of primary amygdala neurons.

\section{Rat protocol 2}

The male offspring (8 weeks old) from the VEH and LNG groups in rat protocol 1 were anesthetized with a mixture of ketamine $(90 \mathrm{mg} / \mathrm{kg})$ and xylazine $(2.7 \mathrm{mg} /$ $\mathrm{kg}$ ) and implanted with a guide cannula targeting the amygdala (26 gauge; Plastics One). The following coordinates were chosen for the amygdala: $-2.0 \mathrm{~mm}$ posterior to the bregma, $\pm 4.2 \mathrm{~mm}$ from the midline, and $-7.2 \mathrm{~mm}$ from the skull surface on which it was based. Cannula was attached to the skull with dental acrylic and jeweler's screws and closed with an obturator [24]. An osmotic minipump (Alzet model 2002; flow rate $0.5 \mu \mathrm{l} / \mathrm{h}$; Cupertino, CA) connected to a 26-gauge internal cannula that extended $1 \mathrm{~mm}$ below the guide was implanted and used to deliver ER $\beta$ overexpression ( $\uparrow E R \beta), E R \beta$ knockdown (shER $\beta$ ), or empty (EMP) lentivirus. Vehicle consisting of artificial cerebrospinal fluid (aCSF; $140 \mathrm{mM} \mathrm{NaCl}, 3 \mathrm{mM} \mathrm{KCl}, 1.2 \mathrm{mM} \mathrm{Na} 2 \mathrm{HPO}_{4}, 1 \mathrm{mM}$ $\mathrm{MgCl}_{2}, 0.27 \mathrm{mM} \mathrm{NaH}{ }_{2} \mathrm{PO}_{4}, 1.2 \mathrm{mM} \mathrm{CaCl}_{2}$, and $7.2 \mathrm{mM}$ dextrose, $\mathrm{pH}$ 7.4) was used for the infusion of the lentivirus. Infusion (flow rate $0.5 \mu \mathrm{l} / \mathrm{h}$ ) begun immediately after placement of the minipump. $0.5 \mu \mathrm{l}$ of total $2 \times 10^{3}$ cfu of lentivirus was infused for $1 \mathrm{~h}$. Rats received the infusion of lentivirus to either knockdown or overexpress ER $\beta$. The experimental rats were separated into four groups (10 per group): group 1, VEH offspring with empty control lentivirus infusion (VEH/EMP); group 2, LNG offspring with empty control lentivirus infusion (LNG/EMP); group 3, LNG offspring with ER $\beta$ expression lentivirus infusion (LNG/ $\uparrow E R \beta)$; and group 4 , VEH offspring with ER $\beta$ knockdown lentivirus infusion (VEH/shER $\beta$ ); cannula placement was verified histologically postmortem by the injection of $0.5 \mu \mathrm{l}$ of India ink (volume matched drug delivery in the experiments). Rats whose dye injections were not located in the amygdala were excluded from the data analysis. Two weeks after the lentivirus infusion, the offspring were used for behavior tests followed by biomedical analysis, as indicated in rat protocol 1.

\section{Animal behavior test}

The animal behavior test of offspring was carried out at 10 weeks of age. Female offspring were tested in the diestrus phase, which was confirmed by vaginal smears. Autism-like behavior was evaluated using the marbles burying test (MBT), social interaction (SI) test, elevated plus maze (EPM), and open-field test $[25,26]$.

\section{Marbles burying test}

In brief, each rat is placed in a clean cage $\left(35 \times 23 \times 19 \mathrm{~cm}^{3}\right)$ filled with wood chip bedding to a depth of $5 \mathrm{~cm}$ containing 
20 colored glass marbles $(1 \mathrm{~cm}$ diameter $)$ placed in a $5 \times 4$ arrangement. The number of marbles buried $(>50 \%$ covered by bedding material) in $30 \mathrm{~min}$ was hand-scored by the experimenter $[25,27]$.

\section{Social interaction test}

In short, the subjects (test and stranger) were separately habituated to the arena for 5 min before the test. During each test, the rats were placed into the apparatus over a period of $20 \mathrm{~min}$ and the time spent following, mounting, grooming, and sniffing any body parts of the other rat was taken as an indicator of social engagement, and was hand-scored by the experimenter. The animal used as the "stranger" was used only once and was a Sprague-Dawley rat of the same gender, weight, and age, with no previous contact with the test rats $[25,27]$.

\section{Elevated plus maze}

All behavioral tests were performed when the rats were 10 weeks old. To investigate the presence of anxiety-like behavior in male and female offspring, the EPM test, a well-established rodent model used to characterize anxiety-like behavior, was performed. The Elevated Plus Maze Package with IR Beam Detection for Rat (Cat \#: MED-ELVM-1R) was obtained from Med Associates Inc. The maze is comprised of two open and two closed arms. Dual sensors at the entrance to each goal runway allow software to differentiate between runway exploration and entrance, resulting in more accurate position detection. The rats were placed in the junction area, and their movements were measured for 5 min using infrared beams installed on each arm and automatically registered by the MED-PC software (Cat \#: SOF-735, Med Associates) for further analysis [24].

\section{Open-field test}

Immediately following the EPM, the rats were tested in an open-field arena using the Open Field Starter Package for Rat (Cat \#: MED-OFA-RSU, Med Associates Inc.). The open-field arena consists of fixed position walls mounted to the system base. Animal movement is tracked using three of 16 beam IR arrays. IR beams are located on both the $X$ and $Y$ axes for positional tracking and the $Z$ axis for rearing detection. The animals were placed in the center of an open field, and exploration was assessed for $30 \mathrm{~min}$. The dimensions of the arena were $40 \mathrm{~cm} \times 40 \mathrm{~cm}$, of which the peripheral $10 \mathrm{~cm}$ were considered the peripheral zone and the central $20 \mathrm{~cm}$ were considered the central zone [24].

\section{In vitro primary culture of amygdala neurons}

Ten-week-old offspring were used for the preparation of primary amygdala neurons. Amygdala tissues were dissected from rat offspring that were humanely sacrificed through cervical dislocation. The tissues were treated with $0.05 \%$ trypsin EDTA for $15 \mathrm{~min}$ at $37{ }^{\circ} \mathrm{C}$. Trypsin EDTA was replaced with soybean trypsin inhibitor (Sigma) for $5 \mathrm{~min}$ at $37{ }^{\circ} \mathrm{C}$ to stop the reaction. This was then replaced with supplemented Neurobasal A (Invitrogen) followed by mechanical dissociation. The cells were then resuspended in culture media, including Neurobasal A, B27, 1×GlutaMAX and $100 \mathrm{U} / \mathrm{ml}$ Pen/Strep (from Invitrogen), and then, the cells were incubated at $37^{\circ} \mathrm{C}$, $5 \% \mathrm{CO}_{2}$ [28]. The isolated amygdala neurons were used for the analysis of DNA methylation, epigenetic changes by chromatin immunosuppression (ChIP) assay on the ER $\beta$ promoter, and in vitro fatty acid lipid uptake.

\section{RT reaction and real-time quantitative $P C R$}

Total RNA from the amygdala was extracted using the RNeasy Micro Kit (Qiagen), and the RNA was reversetranscribed using an Omniscript RT kit (Qiagen). All the primers were designed using Primer 3 Plus software with the Tm at $60{ }^{\circ} \mathrm{C}$, the primer size of $21 \mathrm{bp}$, and the product length in the range of 140-160 bp (see Additional file 1: Table S1). The primers were validated with the amplification efficiency in the range of 1.9-2.1, and the amplified products were confirmed with agarose gel. The real-time quantitative PCR was run on iCycleriQ (Bio-Rad) with the Quantitect SYBR green PCR kit (Qiagen). The PCR was performed by denaturation at $95{ }^{\circ} \mathrm{C}$ for $8 \mathrm{~min}$, followed by 45 cycles of denaturation at $95{ }^{\circ} \mathrm{C}$, annealing at $60{ }^{\circ} \mathrm{C}$, and extension at $72{ }^{\circ} \mathrm{C}$ for $10 \mathrm{~s}$, respectively. One microliter of each cDNA was used to measure target genes. The $\beta$-actin was used as the housekeeping gene for transcript normalization, and the mean values were used to calculate relative transcript levels with the ${ }^{\Delta \Delta} \mathrm{CT}$ method per instructions from Qiagen. In brief, the amplified transcripts were quantified by the comparative threshold cycle method using $\beta$-actin as a normalizer. Fold changes in gene messenger RNA (mRNA) expression were calculated as $2^{-\Delta \Delta C T}$ with $C T=$ threshold cycle, $\Delta \mathrm{CT}=\mathrm{CT}$ (target gene)-CT ( $\beta$-actin), and the $\Delta \Delta \mathrm{CT}=$ $\Delta \mathrm{CT}$ (experimental)- $\Delta \mathrm{CT}$ (reference).

\section{Western blotting}

The amygdala tissues were lysed in an ice-cold lysis buffer $(0.137 \mathrm{M} \mathrm{NaCl}, 2 \mathrm{mM}$ EDTA, $10 \%$ glycerol, $1 \% \mathrm{NP}$ 40, $20 \mathrm{mM}$ Tris base, $\mathrm{pH}$ 8.0) with protease inhibitor cocktail (Sigma). The proteins were separated in 10\% SDS-PAGE and further transferred to the PVDF membrane. The membrane was incubated with appropriate antibodies and washed and incubated with HRP-labeled secondary antibodies, and then, the blots were visualized using the ECL+plus Western Blotting Detection System (Amersham). The blots were quantitated by IMAGEQUANT, and the results were normalized by $\beta$-actin. 


\section{SOD2 activity assay}

The SOD2 was obtained from the mitochondrial fraction that was isolated using a Pierce Mitochondria Isolation Kit (Pierce) per manufacturers' instructions. The SOD activity was measured as described previously [29]. In brief, a stable $\mathrm{O}_{2}^{-}$source was generated through the conversion action of XOD (xanthine oxidase) from xanthine and was mixed with chemiluminescent $(\mathrm{CL})$ reagents to achieve a stable light emission. The SOD2 sample injection can scavenge $\mathrm{O}_{2}^{-}$, and the subsequent decrease of chemiluminescent response is proportional to SOD2 activity. This system can have a detection limit of $0.001 \mathrm{U} \mathrm{ml}^{-1}$ with the linear range of $0.03 \sim 2.00 \mathrm{U} \mathrm{ml}^{-1}$. The results were normalized by protein concentration and were expressed as units per milligram proteins $(\mathrm{U} / \mathrm{mg})$.

\section{In vivo superoxide anion $\left(\mathrm{O}_{2}^{-}\right)$release}

Superoxide anion release from the amygdala tissue was determined by a luminol-EDTA-Fe enhanced chemiluminescence (CL) system supplemented with DMSOTBAC (dimethyl sulfoxide-tetrabutyl ammonium chloride) solution for extraction of released $\mathrm{O}_{2}^{-}$from tissues, as described previously. The superoxide levels were calculated from the standard curve generated by the xanthine/xanthine oxidase reaction [30].

\section{Measurement of DNA breaks}

The 8-OHdG formation was measured using an OxiSelect $^{\mathrm{m}}$ Oxidative DNA Damage ELISA Kit (Cat No. STA320, from Cell Biolabs Inc.) per manufacturers' instructions. The formation of $\gamma \mathrm{H} 2 \mathrm{AX}$ was measured from nuclear extracts by western blotting using H2AX as the input control.

\section{Evaluation of mitochondrial function}

Mitochondrial DNA copies. The genomic DNA was extracted from the amygdala tissue using a QIAamp DNA Mini Kit (Qiagen), and the mitochondrial DNA was extracted using the REPLI-g Mitochondrial DNA Kit (Qiagen). The purified DNA was used for the analysis of genomic $\beta$-actin (marker of the nuclear gene) and ATP6 (ATP synthase F0 subunit 6, marker of the mitochondrial gene), respectively, using the qPCR method mentioned above. The primers for genomic $\beta$-actin: forward 5 '-acc aca gct gag agg gaa atc-3' and reverse 5 '-att gcc gat agt gat gac $\operatorname{ctg}-3^{\prime}$. The primers for ATP6 are forward $5^{\prime}$ - tag ggc ttc ttc ccc ata cat-3' and reverse $5^{\prime}$-tta gtg aga tgg ggg ttc ctt- $3^{\prime}$. The mitochondrial DNA copies were obtained from relative ATP6 copies that were normalized by $\beta$-actin copies using the ${ }^{\Delta \Delta} \mathrm{CT}$ method.

Intracellular ATP level. The intracellular ATP level was determined using the luciferin-/luciferase-induced bioluminescence system. An ATP standard curve was generated at concentrations of $10^{-12}$ to $10^{-3} \mathrm{M}$. Intracellular
ATP levels were calculated and expressed as nanomole per milligram protein [30].

\section{DNA methylation analysis}

We developed a real-time PCR-based method for methylation-specific PCR (MSP) analysis on the rat ER $\beta$ promoter according to the previously described method with some modifications [31-33]. The rat genomic DNA from the amygdala was extracted and purified and then treated by bisulfite modification using the EpiJET Bisulfite Conversion Kit (\#K1461, Fisher). The modified DNA was then amplified using methylated and unmethylated primers for MSP that were designed using the Methprimer software (http://www.urogene.org/cgi-bin/methprimer/methprimer.cgi) with the below details: methylated primer forward 5'-TTT TTT TTA GGT TTT TAA AAG ACG T-3', reverse 5' -ATA CCA ATA ACA ACA CCA ACC G-3', unmethylated primer forward $5^{\prime}$-TTT TTT TTA GGT TTT TAA AAG ATG T-3', and reverse $5^{\prime}$-AAT ACC AAT AAC AAC ACC AAC CAC T-3', the product size 194 bp (methylated) and $195 \mathrm{bp}$ (unmethylated), $\mathrm{CpG}$ island size $134 \mathrm{bp}$, and $\mathrm{Tm} 68-70{ }^{\circ} \mathrm{C}$. The final methylation readout was normalized by unmethylated input PCR, the PCR products were confirmed by electrophorese using $2 \%$ agarose gel, and the DNA bands were imaged.

\section{Chromatin immunoprecipitation}

Cells were washed and crosslinked using $1 \%$ formaldehyde for $20 \mathrm{~min}$ and terminated by $0.1 \mathrm{M}$ glycine. Cell lysates were sonicated and centrifuged. Five hundred micrograms of protein were pre-cleared by BSA/salmon sperm DNA with preimmune IgG and a slurry of protein A agarose beads. Immunoprecipitations were performed with the indicated antibodies, BSA/salmon sperm DNA, and a $50 \%$ slurry of protein A agarose beads. Input and immunoprecipitates were washed and eluted, then incubated with $0.2 \mathrm{mg} / \mathrm{ml}$ proteinase $\mathrm{K}$ for $2 \mathrm{~h}$ at $42{ }^{\circ} \mathrm{C}$, followed by $6 \mathrm{~h}$ at $65{ }^{\circ} \mathrm{C}$ to reverse the formaldehyde crosslinking. DNA fragments were recovered by phenol/ chloroform extraction and ethanol precipitation. A $140 \mathrm{bp}$ fragment in the range of $-200 \sim 0$ from the transcription start site on the rat ER $\beta$ promoter was amplified by real-time PCR (qPCR) using the below primers: forward $5^{\prime}$-ggg tgt $\mathrm{ccc}$ tag tgg atg act-3' and reverse 5 '-aaa aga gtg tgg gag ggt agc-3'.

\section{Evaluation of fatty acid metabolism}

In vitro lipid transport assay. Primary amygdala neurons were seeded in a 12-well plate and grew until they were $80 \%$ confluent. After treatment, $0.5 \mathrm{mCi}^{\text {well }}{ }^{-1}$ of ${ }^{14} \mathrm{C}$ oleic acid (OA) from PerkinElmer was added. After $4 \mathrm{~h}$ of incubation, the cells were washed and harvested, and 
the total radioactivity was quantitated by scintillation counting [34].

Rate of fatty acid oxidation from tissues. The fatty acid oxidation (FAO) rate was measured by evaluation of palmitate oxidation using published methods with minor modifications $[35,36]$. In brief, the amygdala tissue was homogenized, and $30 \mu \mathrm{l}$ of tissue homogenate were then incubated in $370 \mu \mathrm{l}$ of DMEM containing $0.5 \% \mathrm{BSA} /$ $0.2 \mathrm{mM}$ palmitate/0.5 $\mathrm{\mu Ci} / \mathrm{ml} 1{ }^{14} \mathrm{C}$-palmitate at $37{ }^{\circ} \mathrm{C}$ for $2 \mathrm{~h}$. The incubation was stopped by the injection of $0.2 \mathrm{ml}$ of $40 \%$ perchloric acid into the tube to acidify the medium and liberate the $\mathrm{CO}_{2}$. The $\mathrm{CO}_{2}$ was trapped by a filter paper saturated with $20 \mu \mathrm{L}$ of $1 \mathrm{M} \mathrm{NaOH}$ located on the top of the cap. After overnight isotopic equilibration at room temperature, the filter was removed, and the trapped ${ }^{14} \mathrm{CO}_{2}$ and ${ }^{14} \mathrm{C}$ acid-soluble products generated by the oxidation of $\left[{ }^{14} \mathrm{C}\right]$ palmitate were counted to calculate the total palmitate oxidation. The protein concentrations were measured, and the results were expressed as nanomole per milligram proteins per hour (nmol/mg/h).

\section{Statistical analysis}

The data was given as mean \pm SEM, and all the experiments were performed at least in quadruplicate unless indicated otherwise. In order to evaluate the effects of different hormonal treatments on the examined parameters in both males and females, the two-way analysis of variance (ANOVA) followed by the Bonferroni post hoc test was used; to evaluate the effects of hormonal treatments on the examined parameters in either males or females only, the one-way ANOVA followed by the Tukey -Kramer test was used to determine statistical significance of different groups by SPSS 22 software, and a $P$ value of $<0.05$ was considered significant.

\section{Results}

Prenatal levonorgestrel exposure suppresses ER $\beta$ expression and its target genes in the amygdala in male offspring (10 weeks old) and has less of an effect on female offspring

We first evaluated the effect of prenatal exposure of COC on the expression of ER $\beta$ and its target genes in the limbic system in the offspring. Three-month-old pregnant dams were exposed to LNG (20 $\mu \mathrm{g}$ levonorgestrel), EE $(10 \mu \mathrm{g}$ ethinyl estradiol), LNG/EE (20 $\mu \mathrm{g}$ LNG and $10 \mu \mathrm{g}$ EE combination), or VEH (the same volume of vehicle) through subcutaneous daily injections of $0.1 \mathrm{ml}$ for 21 days until pup delivery. The limbic system, including the hypothalamus, hippocampus, and amygdala, were isolated for the analysis of gene expression. In Additional file 1: Table S2, we measured the gene expression of AR (androgen receptor), ER $\alpha$ (estrogen receptor $\alpha$ ), and GPER1 (G proteincoupled estrogen receptor-1) from the hypothalamus, hippocampus, and amygdala, the brain areas known to be involved in the regulation of mood behavior. The results showed that there was no difference in expression in either male or female offspring. We also measured the gene expression of ER $\beta$ and its target genes, including SOD2 and ERR $\alpha$ in the hypothalamus and hippocampus from both male and female offspring (see Additional file 1: Figure S1), and found that there was no difference in those genes. We then measured the mRNA expression of ER $\beta$ (see Fig. 1a) and its target genes SOD2 (see Fig. 1b) and ERR $\alpha$ (see Fig. 1c) in the amygdala. We found that treatment of either LNG alone or LNG/EE combination significantly suppressed the expression of ER $\beta$, SOD2, and ERR $\alpha$ in male offspring, and EE alone had no effect. On the other hand, in female offspring, LNG alone could still significantly suppress these genes but had a much smaller effect compared to that in male offspring, and EE alone and LNG/EE combination had no effect. We then measured the protein levels in the amygdala from both male and female offspring. The results showed that protein levels of ER $\beta$ and its target genes SOD2 and ERR $\alpha$ were suppressed significantly in male offspring by treatment of LNG alone and LNG/EE combination, and EE alone had no effect (see Fig. 1d, e). On the other hand, there was much less of an effect in female offspring. LNG alone slightly decreased protein expression, while LNG/EE combination and EE alone showed no effect on protein expression (see Fig. 1f, g). We finally measured the SOD2 activity (see Fig. 1h), and similar patterns, like SOD2 protein expression, were observed. SOD2 activity decreased significantly in LNG and LNG/EE treatment in male offspring, while in female offspring, only LNG alone slightly decreased activity, and LNG/EE and EE treatment showed no effect (see detailed statistical information in Additional file 1: Data S1). Our results suggest that LNG may play a dominant role in prenatal exposure of COC-induced ER $\beta$ suppression in the amygdala in offspring, while EE seems to have no effect, and that females are less responsive to prenatal LNG exposure, compared to male offspring.

\section{Prenatal levonorgestrel exposure induces ER $\beta$ suppression in the amygdala through increased methylation on the ER $\beta$ promoter, while EE has no effect} We measured DNA methylation on the ER $\beta$ promoter using methylation-specific PCR (MSP) analysis. In Fig. 2a, b, both LNG and LNG/EE treatments significantly increased DNA methylation on the ER $\beta$ promoter in amygdala neurons from both male and female offspring (10 weeks old), while EE treatment had no effect. On the other hand, there was much less of an effect on DNA methylation with the LNG/EE treatment in females compared in males. We then measured the epigenetic changes on the ER $\beta$ promoter using ChIP techniques. The results showed significantly 


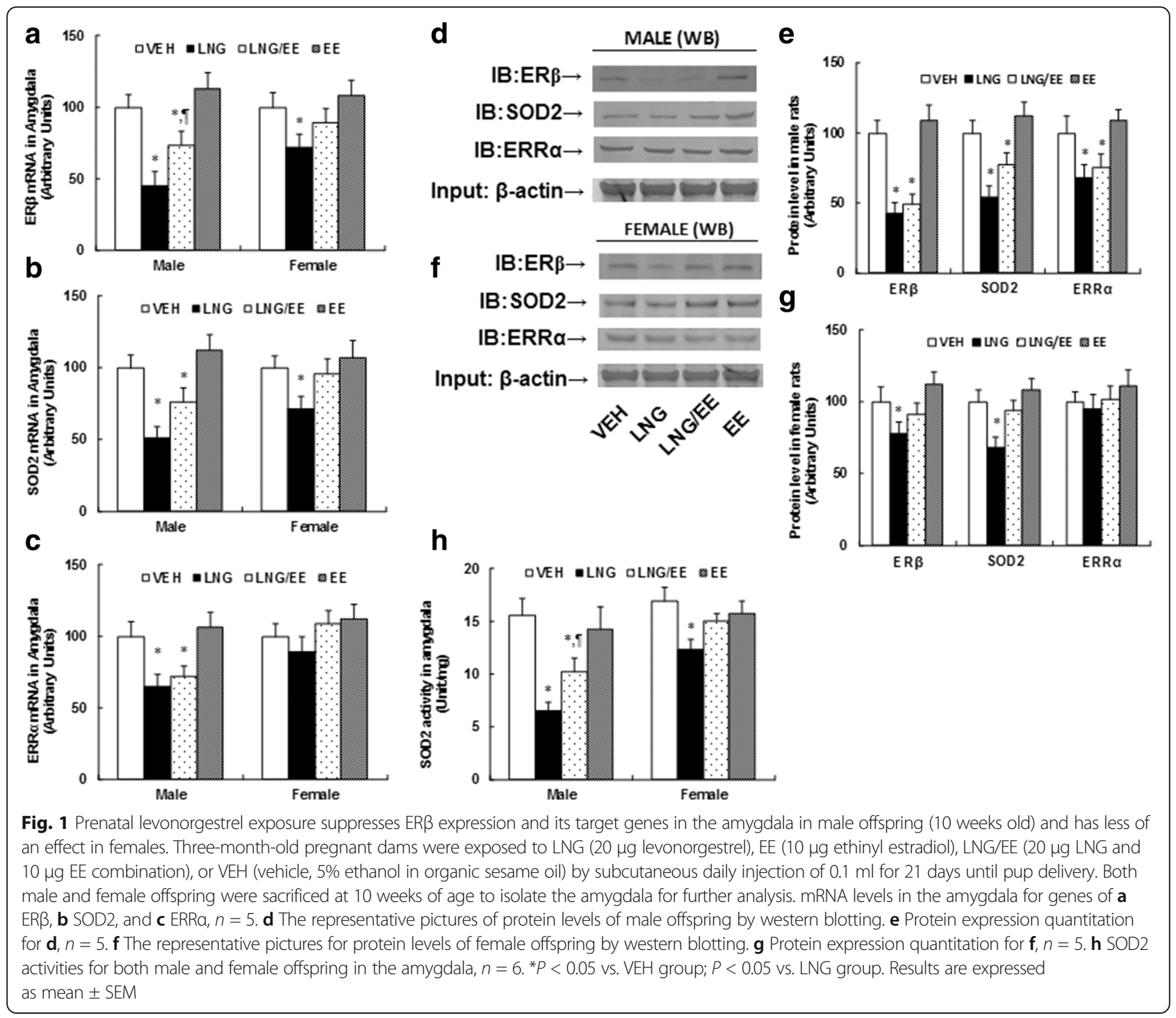

increased H3K9 di-methylation (H3K9me2) and H3K27 trimethylation (H3K27me3) on the ER $\beta$ promoter from both male (see Fig. 2c) and female offspring (see Fig. 2d) with LNG alone and LNG/EE combination treatment, while EE had no effect (see detailed statistical information in Additional file 1: Data S2). Our results indicate that prenatal levonorgestrel exposure-induced ER $\beta$ suppression in amygdala neurons is due to increased DNA methylation on the ER $\beta$ promoter.

Prenatal levonorgestrel exposure induces ROS generation and DNA damage, along with dysfunction of mitochondria and fatty acid metabolism in the amygdala in male offspring ( 10 weeks old), while there is less of an effect in female offspring

We evaluated the molecular consequences of prenatal levonorgestrel exposure-induced ER $\beta$ suppression in the amygdala in both male and female offspring. We showed that prenatal levonorgestrel exposure (both LNG and LNG/EE treatment) significantly increased superoxide anion $\left(\mathrm{O}_{2}^{-}\right)$release from amygdala tissues (see Fig. 3a), 3-nitrotyrosine formation (see Fig. 3b), 8-OHdG formation (see Fig. 3c), and DNA damage with $\gamma \mathrm{H} 2 \mathrm{AX}$ formation (see Fig. 3d, e); it also suppressed mitochondrial function, including decreased mitochondrial DNA copies (see Fig. 3f) and intracellular ATP level (see Fig. 3g). Furthermore, it suppresses fatty acid metabolism, including decreased in vivo fatty acid oxidation (see Fig. 3h) and in vitro fatty acid uptake (see Fig. 3i). Interestingly, there was much less damage in the amygdala in female offspring than in male offspring, which is consistent with the ER $\beta$ expression in the amygdala (see detailed statistical information in Additional file 1: Data S3). These results indicate that prenatal levonorgestrel exposure-induced ER $\beta$ suppression in both male and female offspring (10 months old) may contribute to LNG-mediated molecular damage in the amygdala. 


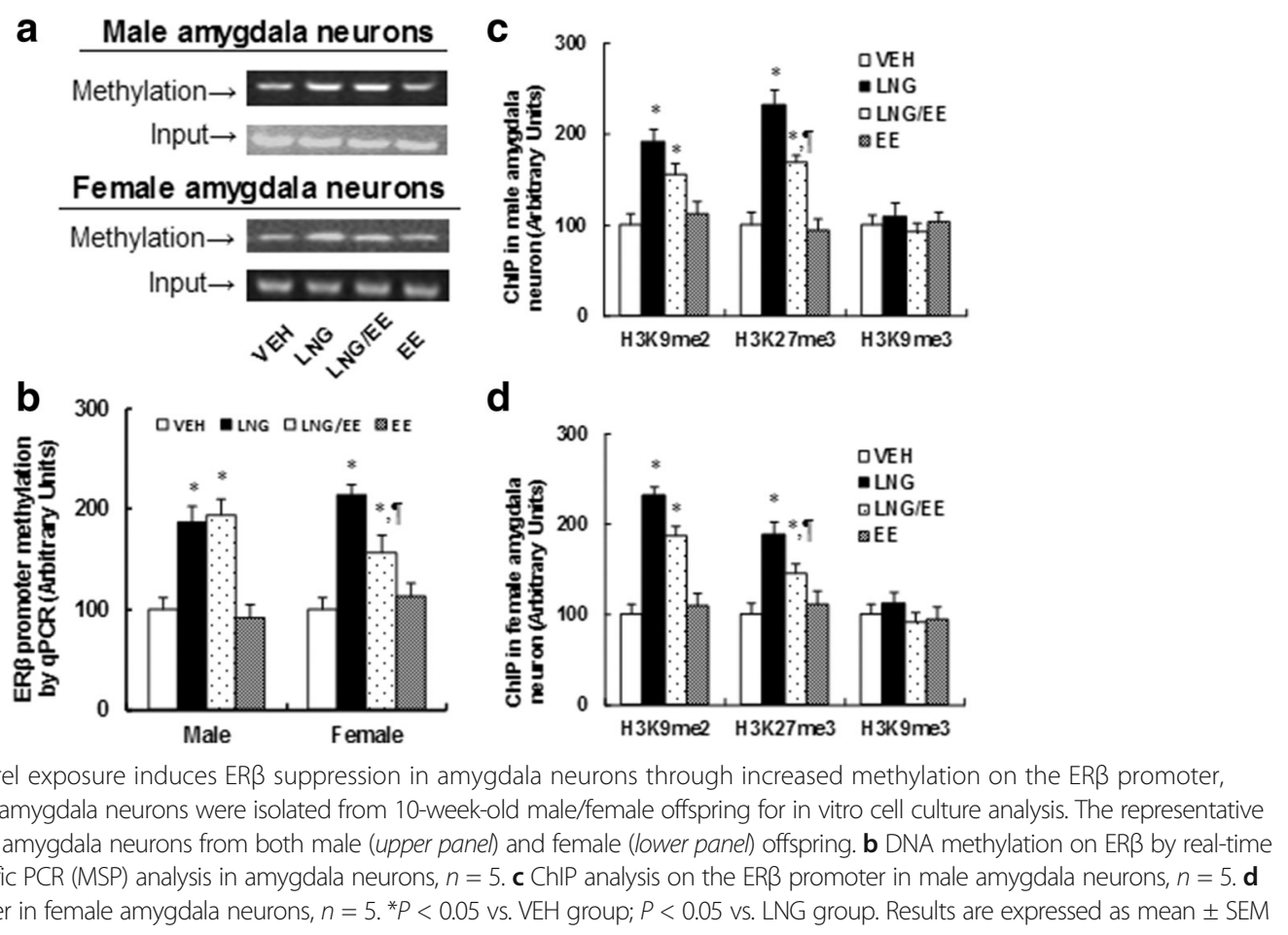

Prenatal levonorgestrel exposure induces autism-like behavior in male offspring (10 weeks old), while there is less of an effect in female offspring

We measured the effect of prenatal levonorgestrel exposure on autism-like behavior in offspring. The male offspring that received the LNG and LNG/EE treatment had significant less buried marbles (see Fig. 4a) and interaction time (see Fig. 4b) and spent significantly less time in the open arm (see Fig. 4c) and more time in the closed arm (see Fig. 4d) in the EPM (elevated plus maze) test compared to the vehicle-treated animals (VEH). Also, the male offspring spent less time in the central area (see Fig. 4e) and more time in the peripheral area (see Fig. 4f) but without changes in total horizontal locomotor activity (see Fig. 4g) in the open-field test. On the other hand, the female offspring were less responsive, as LNG treatment only slightly induced autism-like behavior, while LNG/EE and EE treatment showed little effect. Our results indicate that male offspring are more sensitive to prenatal levonorgestrel exposureinduced autism-like behavior. The detailed statistical information is shown below:

In Fig. 4a, two-way ANOVA revealed significant effect of sex $[F(1,56)=4.594, P=0.031]$ and a significant effect on treatment $[F(3,56)=5.918, P<0.01]$, and there was a significant interaction $[F(3,56)=4.110$, $P=0.042]$. Subsequent post hoc analysis revealed that LNG and LNG/EE decreased buried marbles in male offspring $(-50 \%,-40 \%$ vs. VEH group, respectively, $p<0.01$ ), and the female offspring had significant less response in $\mathrm{VEH}$ and $\mathrm{EE}$ treatments compared to male offspring $(p<0.01)$.

In Fig. 4b, two-way ANOVA revealed significant effect of sex $[F(1,56)=3.849, P=0.041]$ and a significant effect on treatment $[F(3,56)=5.101, P=0.019]$, and there was a significant interaction $[F(3,56)=3.917$, $P=0.027]$. Subsequent post hoc analysis revealed that LNG and LNG/EE decreased interaction time in male offspring $(-26 \%,-33 \%$ vs. VEH group, respectively, $p<0.05)$; LNG decreased interaction time in female offspring $(-35 \%$ vs. VEH group, $p<0.01)$, and the female offspring had significant less response in LNG/EE treatment compared to the male offspring $(p<0.01)$.

In Fig. 4c, two-way ANOVA revealed no significant effect of $\operatorname{sex}[F(1,56)=2.194, P=0.061]$ and a significant effect on treatment $[F(3,56)=3.691, P=0.037]$, no significant interaction $[F(3,56)=2.114, P=0.167]$. Subsequent post hoc analysis revealed that LNG and LNG/EE decreased time in open arm in male offspring $(-22 \%$, $-16 \%$ vs. VEH group, respectively, $p<0.05)$, and LNG decreased time in open arm in female offspring $(-15 \%$ vs. VEH group, $p<0.05$ ).

In Fig. 4d, two-way ANOVA revealed significant effect of $\operatorname{sex}[F(1,56)=4.195, P=0.023]$ and a significant effect on treatment $[F(3,56)=6.348, P<0.01]$, and there was a significant interaction $[F(3,56)=3.987$, $P=0.023$. Subsequent post hoc analysis revealed that LNG and LNG/EE increased time in closed arm in male 


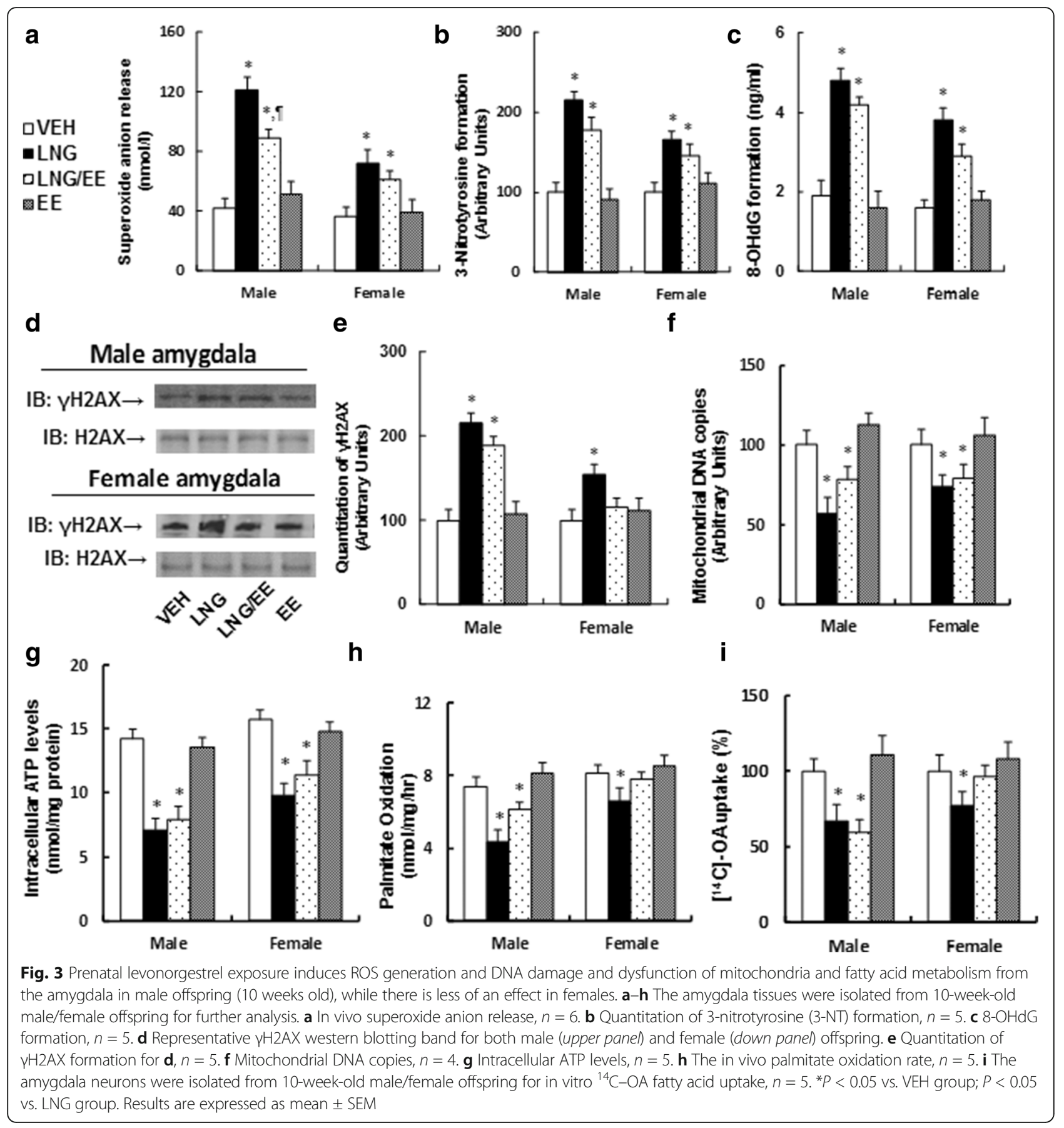

offspring $(+186 \%,+164 \%$ vs. VEH group, respectively, $p<0.05)$; and LNG increased time in closed arm in female offspring $(+146 \%$ vs. VEH group, $p<0.05)$, and the female offspring had significant less response in LNG/EE treatment compared to male offspring $(p<0.05)$.

In Fig. 4e, two-way ANOVA revealed significant effect of sex $[F(1,64)=3.447, P=0.042]$ and a significant effect on treatment $[F(3,64)=3.915, P=0.036]$, and there was no significant interaction $[F(3,64)=2.138$, $P=0.194]$. Subsequent post hoc analysis revealed that
LNG and LNG/EE decreased central time in male offspring $(-17 \%,-27 \%$ vs. VEH group, respectively, $p<0.05)$; LNG decreased central time in female offspring $(-21 \%$ vs. VEH group, $p<0.05)$, and the female offspring had significant less response in LNG/EE treatment compared to male offspring $(p<0.05)$.

In Fig. 4f, two-way ANOVA revealed significant effect of sex $[F(1,64)=3.461, P=0.043]$ and a significant effect on treatment $[F(3,64)=3.612, P=0.037]$, and there was a significant interaction $[F(3,64)=4.016$, 


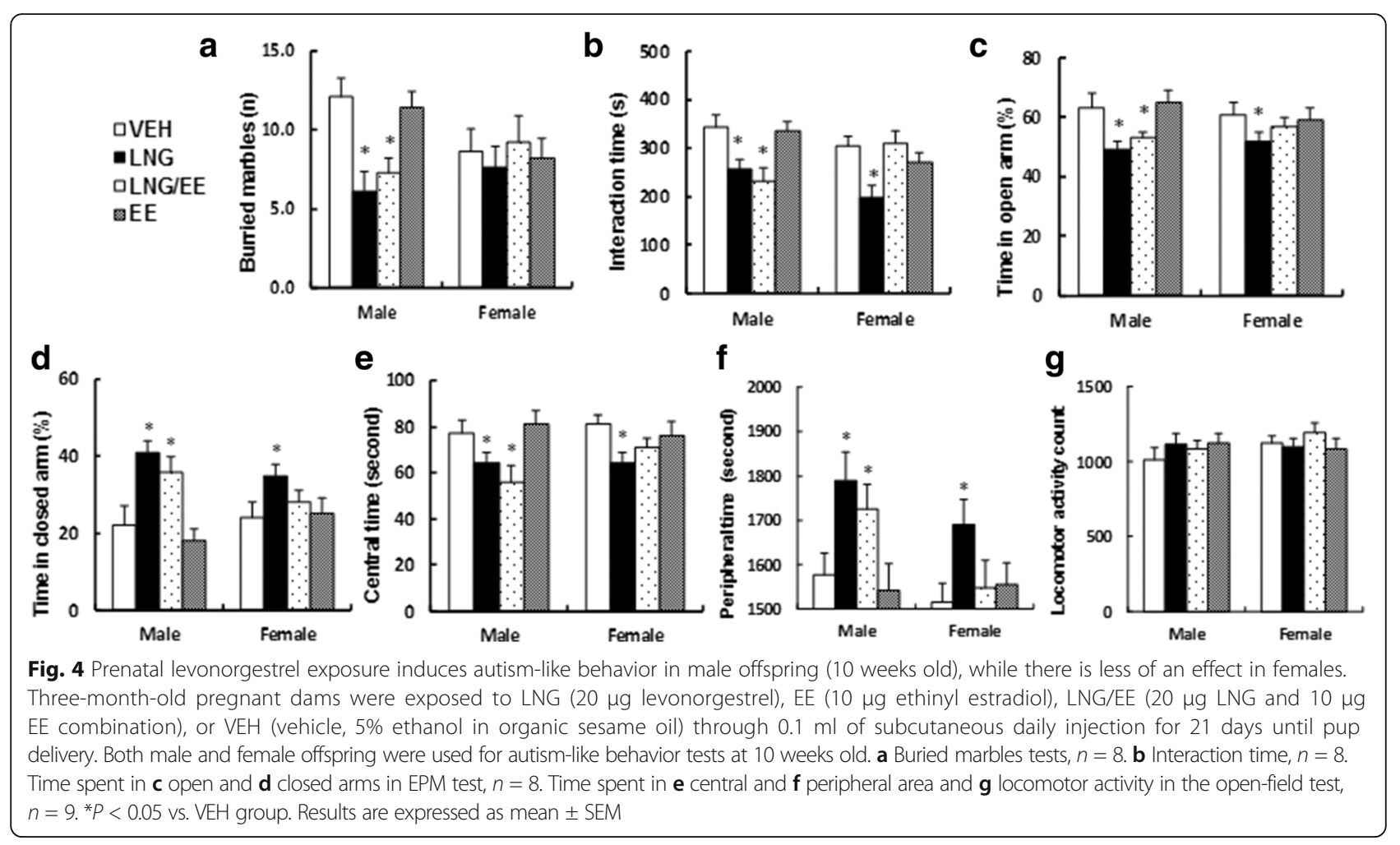

$P=0.031]$. Subsequent post hoc analysis revealed that LNG and LNG/EE increased peripheral time in male offspring $(+13 \%,+9 \%$ vs. VEH group, respectively, $p<0.05)$; LNG increased peripheral time in female offspring $(+11 \%$ vs. VEH group, $p<0.05)$, and the female offspring had significant less response in LNG/EE treatment compared to male offspring $(p<0.05)$.

In Fig. 4g, two-way ANOVA revealed no significant effect of sex $[F(1,64)=1.021, P=0.561]$ and no significant effect on treatment $[F(3,64)=1.014, P=0.947]$ and no interaction $[F(3,64)=0.948, P=1.041]$.

Overexpression of ER $\beta$ in the amygdala restores prenatal levonorgestrel exposure-induced ROS generation and DNA damage, along with dysfunction of mitochondria and fatty acid metabolism in 10-week-old offspring, while ER $\beta$ knockdown mimics the effect

The 8-week-old male offspring from dams that were treated by either VEH or LNG received either EMP, ER $\beta$ overexpression $(\uparrow E R \beta)$, or knockdown $(\operatorname{shER} \beta)$ lentivirus infusion to the amygdala, and the offspring were sacrificed at 10 weeks of age for analysis of gene expression and the subsequent molecular consequences. Our results showed that the gene expression of ER $\beta$ and its target genes SOD2 and ERR $\alpha$, including mRNA (see Fig. 5a) and protein levels (see Fig. 5b, c), decreased significantly in LNG/EMP treatment compared to that in the VEH/EMP group, and the expression increased in the LNG/ $\uparrow \mathrm{ER} \beta$ group but decreased in the VEH/shER $\beta$ group. We also measured SOD2 activity (see Fig. 5d), and the results showed that LNG/EMP and VEH/shER $\beta$ treatment decreased SOD2 activity, while LNG/ $\uparrow E R \beta$ group increased SOD2 activity. Our results indicate that the manipulation of ER $\beta$ gene expression in the amygdala through lentivirus infusion was successful and efficient. We then measured the molecular consequences from the male offspring treated by ER $\beta$ lentivirus. Our results showed that LNG/EMP treatment significantly increased ROS formation, including superoxide anion release (see Fig. 5e), 3-nitrotyrosine formation (see Fig. 5f), and DNA damage, including 8OHdG formation (see Fig. 5g) and $\gamma \mathrm{H} 2 \mathrm{AX}$ formation (see Fig. 5h, i). Overexpression of ER $\beta$ (LNG/ $\uparrow \mathrm{ER} \beta$ group) completely normalized this effect compared to the VEH/EMP control group, while ER $\beta$ knockdown (VEH/shER $\beta$ group) mimicked the LNG effect. We then measured the function of mitochondria and fatty acid metabolism. Our results showed that LNG treatment (LNG/EMP group) significantly decreased mitochondrial DNA copies (see Fig. 5j), intracellular ATP levels (see Fig. 5k), in vivo palmitate oxidation rate (see Fig. 5l), and in vitro ${ }^{14} \mathrm{C}-\mathrm{OA}$ fatty acid uptake (see Fig. 5m) compared to the VEH/EMP control group. Again, ER $\beta$ expression (LNG/ $\uparrow E R \beta$ group) completely normalized the effect, and ER $\beta$ knockdown (VEH/ shER $\beta$ group) mimicked the effect (see detailed statistical information in Additional file 1: Data S4). Our results 


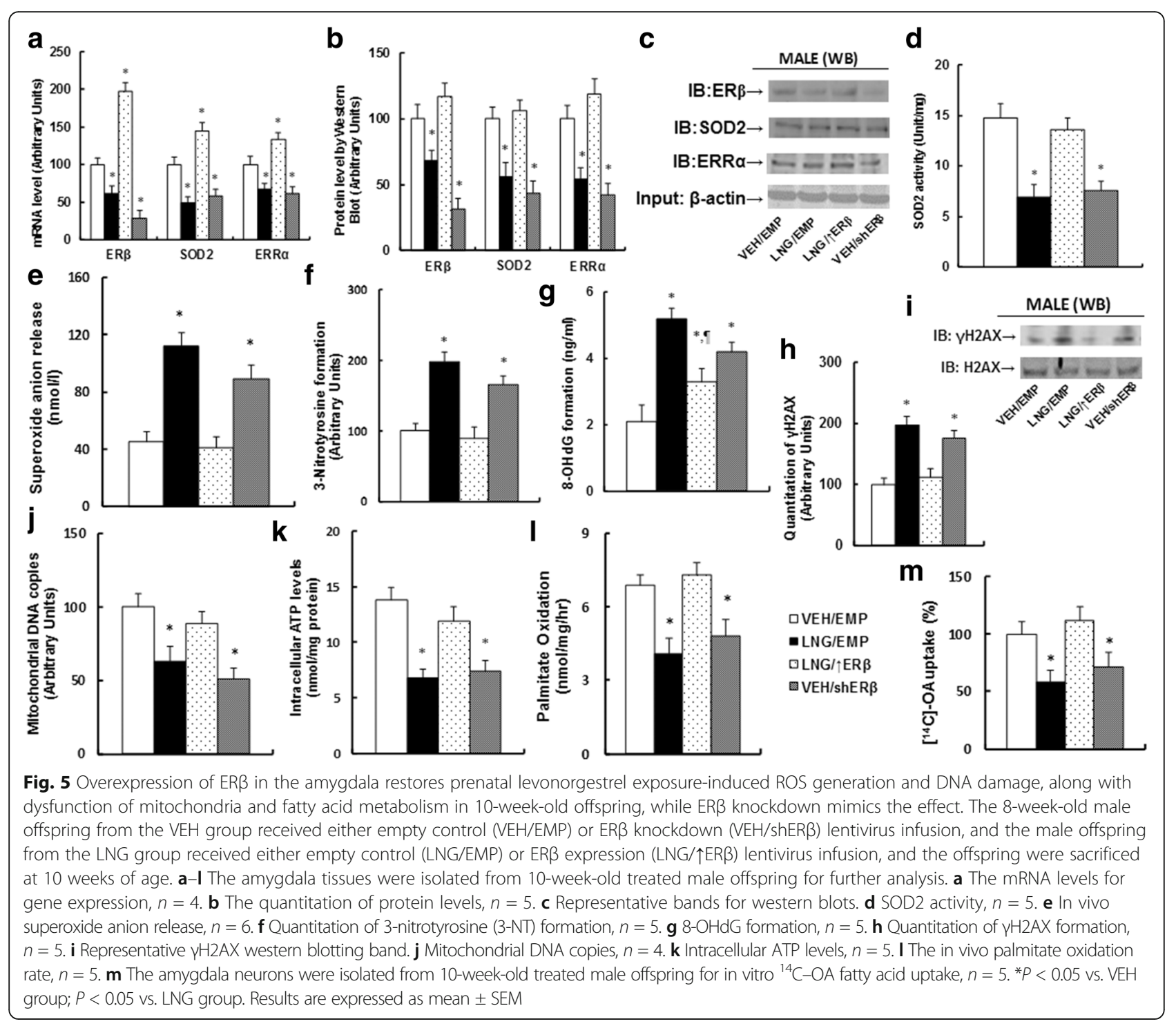

indicate that ER $\beta$ expression in the amygdala plays a major role in prenatal levonorgestrel exposure-mediated molecular dysfunction in offspring.

\section{Overexpression of ER $\beta$ in the amygdala restores prenatal levonorgestrel exposure-induced autism-like behavior in 10-week-old offspring, while ER $\beta$ knockdown mimics the effect}

We measured the effect of ER $\beta$ expression on prenatal levonorgestrel exposure-induced autism-like behavior in offspring. The male offspring from the LNG/EMP treatment had significant less buried marbles (see Fig. 6a) and interaction time (see Fig. 6b) and spent significantly less time in the open arm (see Fig. 6c) and more time in the closed arm (see Fig. 6d) in the EPM test compared to that in the VEH/ EMP control group. The offspring also spent less time in the central area (see Fig. 6e) and more time in the peripheral area (see Fig. 6f), but without changes in total horizontal locomotor activity (see Fig. $6 \mathrm{~g}$ ) in the open-field test. Overexpression of ER $\beta$ (LNG/ $\uparrow E R \beta$ group) completely normalized the effect, while ER $\beta$ knockdown (VEH/shER $\beta)$ mimicked it. Our results indicate that prenatal levonorgestrel exposure-induced autism-like behavior in offspring is due to ER $\beta$ suppression in the amygdala. The detailed statistical information is shown below:

In Fig. 6a, for buried marbles, one-way ANOVA revealed a significant effect $[F(3,31)=8.162, P<0.01]$. Subsequent Tukey analysis revealed that LNG decreased buried marbles $(-59 \%$ vs. VEH group, $p<0.01)$; $\uparrow E R \beta$ increased $(+181 \%$ vs. EMP group, $p<0.01)$, while shER $\beta$ decreased $(-38 \%$ vs. EMP group, $p<0.01)$ buried marbles. 


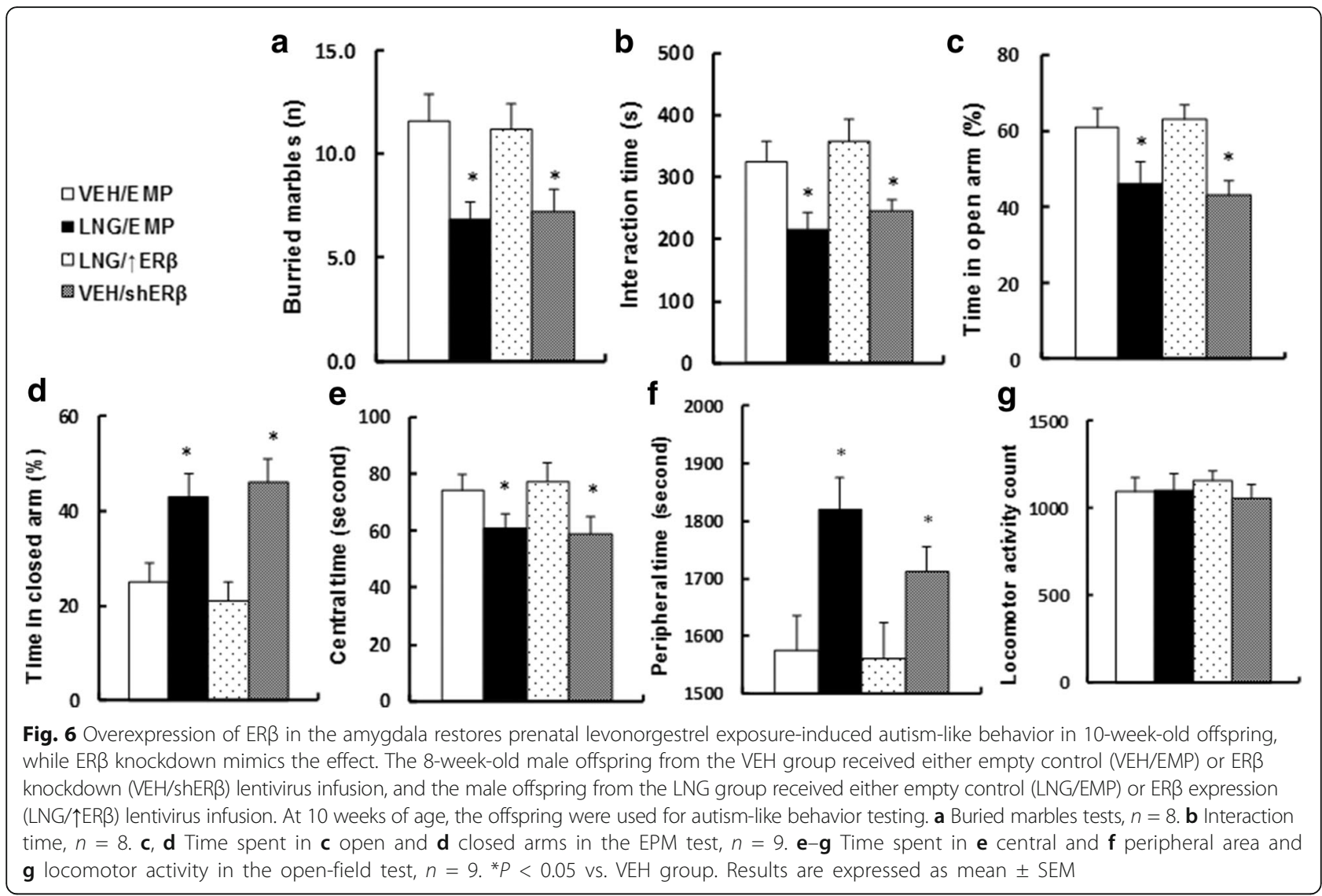

In Fig. 6b, for interaction time, one-way ANOVA revealed a significant effect $[F(3,31)=7.694, P<0.01]$. Subsequent Tukey analysis revealed that LNG decreased interaction time ( $-34 \%$ vs. VEH group, $p<0.01)$; $\uparrow E R \beta$ increased $(+174 \%$ vs. EMP group, $p<0.01)$, while shER $\beta$ decreased $(-25 \%$ vs. EMP group, $p=0.024)$ interaction time.

In Fig. 6c, for time in open arm, one-way ANOVA revealed a significant effect $[F(3,35)=4.367, P=0.032]$. Subsequent Tukey analysis revealed that LNG decreased time in open arm $(-25 \%$ vs. VEH group, $p=0.021)$; $\uparrow E R \beta$ increased $(+137 \%$ vs. EMP group, $p<0.01)$, while $\operatorname{shER} \beta$ decreased $(-30 \%$ vs. EMP group, $p=0.024)$ time in open arm.

In Fig. 6d, for time in closed arm, one-way ANOVA revealed a significant effect $[F(3,35)=8.127, P<0.01]$. Subsequent Tukey analysis revealed that LNG increased time in closed arm $(+172 \%$ vs. VEH group, $p<0.01)$; $\uparrow E R \beta$ decreased $(-52 \%$ vs. EMP group, $p<0.01)$, while shER $\beta$ increased $(+187 \%$ vs. EMP group, $p<0.01)$ time in closed arm.

In Fig. 6e, for central time, one-way ANOVA revealed a significant effect $[F(3,35)=4.361, P=0.037]$. Subsequent Tukey analysis revealed that LNG decreased central time $(-18 \%$ vs. VEH group, $p=0.036)$; $\uparrow E R \beta$ increased $(+126 \%$ vs. EMP group, $p=0.039)$, while $\operatorname{shER} \beta$ decreased $(-21 \%$ vs. EMP group, $p=0.037)$ central time.

In Fig. 6f, for peripheral time, one-way ANOVA revealed a significant effect $[F(3,35)=3.794, P=0.044]$. Subsequent Tukey analysis revealed that LNG increased peripheral time $(+115 \%$ vs. VEH group, $p=0.034) ; \uparrow E R \beta$ decreased $(-14 \%$ vs. EMP group, $p=0.041)$, while shER $\beta$ increased $(+109 \%$ vs. EMP group, $p=0.043)$ peripheral time.

In Fig. $6 \mathrm{~g}$, for locomotor activity, one-way ANOVA revealed no significant effect $[F(3,35)=0.594$, $P=0.791]$.

\section{Discussion}

In this study, we show that the compound LNG used in $\mathrm{COC}$ modifies the fetal condition during the prenatal period through altered methylation with ER $\beta$ suppression in the amygdala. ER $\beta$ suppression results in decreased expression of SOD2 and ERR $\alpha$, and subsequently triggers damage in amygdala tissue through oxidative stress and the dysfunction of mitochondria and fatty acid metabolism, and eventually contributes to autism-like behavior in offspring. 
The amygdala is responsible for storing memories of events for future recognition. It assists in the development of memories, fear emotion, and plays a major role in pleasure and sexual arousal, and many reports have shown that the amygdala is involved in ASD symptoms [37-39]. The functional significance of the changes only localized to the amygdala is social fear and/or anxiety learning $[24,40]$. Our results show that prenatal LNG exposure induces ER $\beta$ suppression in the amygdala with autism-like behavior in offspring [12], and overexpression of ER $\beta$ completely restores this effect. This indicates that ER $\beta$ suppression in the amygdala may be a causative factor for autism-like behavior development. Furthermore, suppression of ER $\beta$ and its target genes, including SOD2 and ERR $\alpha$, results in oxidative stress [41] and dysfunction of mitochondria and fatty acid metabolism [42-44], which may directly or indirectly contribute to tissue damage and the subsequent autism-like behavior development.

\section{Association of oral contraceptives and autism}

The increase in the prevalence of oral contraceptive use in the past 60 years coincides with the recent dramatic rise in autism and ASD prevalence [8], indicating a link between oral contraceptive and ASD. The incidence of mild to moderate depressive syndrome among women taking oral contraceptives is $\sim 10$ to $40 \%$ [45], and several studies demonstrated that oral contraceptives have a negative effect on anxiety, mood, and emotional wellbeing in women [46-49]. It has been reported that longterm administration of combined LNG and EE, two of the most widely used steroids in oral contraceptive pills, is associated with a reduction in social behavior [50]. It is reasonable that the neurochemical changes induced by LNG/EE treatment may contribute to some of the emotional disorders observed in hormonal contraceptive users. The combined oral contraceptive, especially LNG, is used by women to prevent pregnancy after birth control failure. This medication is a progestin hormone that works primarily by preventing the release of an egg (ovulation) during the menstrual cycle. The suppression of ovulation produced by oral contraceptives is an indisputable abnormality [8], while to date, there is no comprehensive research on the potential neurodevelopmental effects of oral contraceptive use on oocyte and progeny. Our study shows that prenatal LNG exposure induces ER $\beta$ suppression in the amygdala in offspring with autism-like behavior, which includes significantly less buried marbles and interaction time in the social behavior test and spending much less time in the open arm and more time in the closed arm in the EPM test, as well as spending less time in the central area and more time in the peripheral area in the open-field test. This indicates that prenatal exposure to oral contraceptives may be a potential risk factor for ASD or related neurodevelopment abnormalities in offspring. On the other hand, we must emphasize that because of the high doses of the hormones administered, as well as the long duration of time, the applicability of these findings to the human condition is limited.

\section{ER $\beta$ suppression may contribute to male predominance in autism}

ASD is much more common in males than in females, with a ratio of $4: 1$. It has been reported that high levels of testosterone during early fetal development may be a risk factor for ASD. This is supported by many studies reporting an association between fetal testosterone levels and autistic features $[24,51,52]$, while the related mechanism is still unknown. ER $\beta$ is largely expressed in brain tissues [53], and it has been recently reported that there are alterations in ER $\beta$ expression in the brain of ASD subjects [14]. ER $\beta$-deficient mice also show increased anxiety [13], indicating that ER $\beta$ may play an important role in ASD development [54]. Our results show that prenatal exposure of EE has no effect on autism-like behavior, which is consistent with previous observations that estrogen is a neuroprotective hormone [55]. On the other hand, prenatal exposure to oral contraceptive LNG induces ER $\beta$ suppression with autism-like behavior in offspring. Furthermore, we show that male offspring are more susceptible to LNG-induced ER $\beta$ suppression with higher autism-like behavior ratio. This may be due to the following reasons: (a) higher endogenous estrogen levels in female offspring partly normalize the testosterone effect of LNG; (b) the female offspring have a higher basal expression of ER $\beta$ compared to male offspring, which is more resistant to LNG-induced ER $\beta$ suppression; and (c) higher estrogen levels in female offspring could activate ER $\beta$ and upregulate its target genes SOD2 and ERR $\alpha$ and subsequently ameliorate tissue damage $[15,16]$ with less responsiveness to autism-like behavior development. In this study, the LNG/EE treatment induces effects like those of LNG in many of the biochemical and behavioral parameters examined, while sometimes in female offspring, the LNG/EE shows an effect to that of EE instead of LNG alone. This may be due to that the potential effect of LNG is partly normalized or antagonized by estrogen.

\section{Potential oral contraceptive exposure from the environment}

Increasing evidence shows that the environment also plays an important role in the etiology of ASD [4]. It has been reported that the concordance rate for ASD in dizygotic twins is around 30\% [56], which is much higher than the $8-17 \%$ concordance rate for non-twin siblings [57], indicating that environmental factors significantly 
contribute to ASD. Recently, specific environmental factors, including prenatal and perinatal exposure factors, have been reported to contribute to increased ASD risk $[24,58]$. In our study, prenatal LNG exposure in dams during pregnancy induces autism-like behavior in offspring, indicating that oral contraceptive exposure may be an important environmental factor in ASD development. Currently in China, other than the intentional uptake of oral contraceptive pills for birth control, another important increasing source of prenatal LNG exposure comes from seafood contaminated with COC. COC has been widely used in China in the seafood industry to prevent the pregnancy of female organisms, such as fish and shrimp, so that they can grow more quickly and become fatter without pregnancy. This may be an important reason for why there is continuously increasing incidence of ASD in China. Pregnant women must be especially careful to avoid eating oral contraceptivecontaminated seafood.

\section{Conclusions}

Altogether, we show that prenatal exposure to oral contraceptive LNG alters DNA methylation on the ER $\beta$ promoter with ER $\beta$ suppression in the amygdala. This subsequently results in tissue damage with oxidative stress and dysfunction of mitochondria and fatty acid metabolism and triggers autism-like behavior in offspring. Meanwhile, EE seems to have no effect, and male offspring are more susceptible than female offspring. Overexpression of ER $\beta$ restores LNG-mediated effects, while ER $\beta$ knockdown mimics the effect. This is the first time the potential effect of prenatal exposure to oral contraceptives on the contribution of autism-like behavior in offspring is discovered.

\section{Additional file}

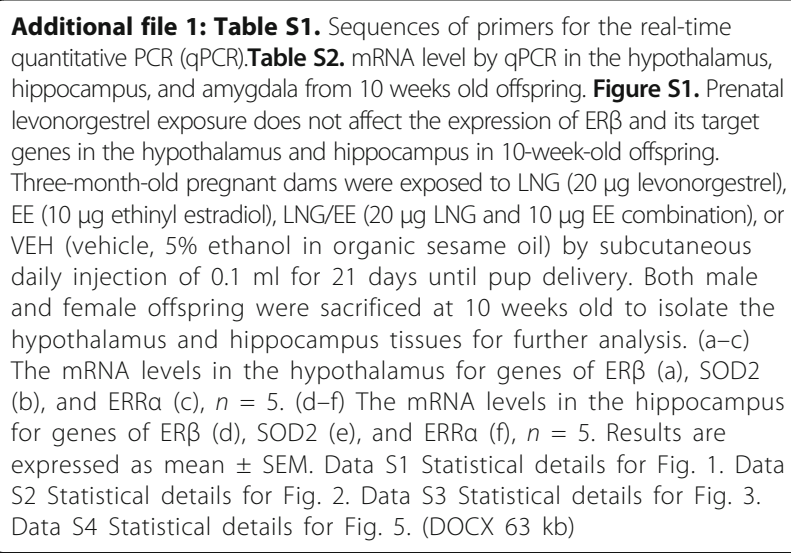

\section{Abbreviations}

AR: Androgen receptor; ASD: Autism spectrum disorder; ChIP: Chromatin immunoprecipitation; COC: Combined oral contraceptives; EE: Ethinyl estradiol; EMP: Empty control; EPM: Elevated plus maze; ERR: Estrogen-related receptor a; ERa: Estrogen receptor a; ERß: Estrogen receptor $\beta$; GPER1: G protein-coupled estrogen receptor-1; LNG: Levonorgestrel; MBT: Marbles burying test; SI: Social interaction; SOD2: Mitochondrial superoxide dismutase; VEH: Vehicle control

\section{Acknowledgements}

Not applicable.

\section{Funding}

This study was financially supported by the National Natural Science Foundation of China, Project \#: 81,501,667\& 81,273,024; the Wuhan Science and Technology Innovation, Project \#: 2,015,070,404,010,214; the Hubei Science \& Technology Development, Project \#: 2016CFB589\& 2016CFB473; the 2013 International Science and Technology Cooperation Project of Ministry of Education (China) \#: 2013 DFA31400; and the Science and Technology Planning Project of Guangdong Province (China) \#: 2016B090918040.

\section{Availability of data and materials}

Not applicable.

\section{Authors' contributions}

$P Y, Y Z$, and $W X$ designed, interpreted the experiments, and wrote the paper. $Z C, Q R, W L$, and $X H$ performed the rat surgery and social behavior testing. $Z Y L, Z Z, Y H$, and $Z X L$ performed the steroid measurement, virus preparation, and western blots analysis. $H C, X G, X Y$, and $Y W$ performed the amygdala isolation and analysis. $Y Z, Q L$, and DZ performed the remaining experiments. All authors read, edited, and approved the final manuscript.

\section{Ethics approval and consent to participate}

The animal protocol conformed to the US NIH guidelines (Guide for the Care and Use of Laboratory Animals, No. 85-23, revised 1996) and was reviewed and approved by the Institutional Animal Care and Use Committee from Tongji Medical College and Wuhan University.

\section{Consent for publication}

Not applicable.

\section{Competing interests}

The authors declare that they have no competing interests.

\section{Publisher's Note}

Springer Nature remains neutral with regard to jurisdictional claims in published maps and institutional affiliations.

\section{Author details}

'Internal Medicine of Tongji Hospital, Tongji Medical College, Huazhong University of Science and Technology, Wuhan 430030, People's Republic of China. ${ }^{2}$ Tongji Wenchang Hospital, Huazhong University of Science and Technology, Wenchang 571321, People's Republic of China. Institute of Environmental Medicine, Tongji Medical College, Huazhong University of Science and Technology, Wuhan 430030, People's Republic of China. ${ }^{4}$ Institute of Burns, Tongren Hospital of Wuhan University, Wuhan 430060, People's Republic of China. ${ }^{5}$ SALIAI Stem Cell Institute of Guangdong, Guangzhou SALIAI Stem Cell Science and Technology Co. LTD, Guangzhou 510055, People's Republic of China.

Received: 21 March 2017 Accepted: 13 July 2017

Published online: 17 August 2017

\section{References}

1. Wang T, Guo H, Xiong B, Stessman HA, Wu H, Coe BP, Turner TN, Liu Y, Zhao W, Hoekzema K, et al. De novo genic mutations among a Chinese autism spectrum disorder cohort. Nat Commun. 2016;7:13316.

2. Abrahams BS, Geschwind DH. Advances in autism genetics: on the threshold of a new neurobiology. Nat Rev Genet. 2008;9(5):341-55.

3. Bodo C, Rissman EF. New roles for estrogen receptor beta in behavior and neuroendocrinology. Front Neuroendocrinol. 2006;27(2):217-32.

4. Schaafsma SM, Pfaff DW. Etiologies underlying sex differences in autism spectrum disorders. Front Neuroendocrinol. 2014;35(3):255-71. 
5. Baron-Cohen S, Knickmeyer RC, Belmonte MK. Sex differences in the brain: implications for explaining autism. Science. 2005;310(5749):819-23.

6. Auyeung B, Taylor K, Hackett G, Baron-Cohen S. Foetal testosterone and autistic traits in 18 to 24-month-old children. Mol Autism. 2010;1(1):11.

7. Sarachana T, Xu M, Wu RC, Hu WW. Sex hormones in autism: androgens and estrogens differentially and reciprocally regulate RORA, a novel candidate gene for autism. PLoS One. 2011;6(2):e17116.

8. Strifert K. The link between oral contraceptive use and prevalence in autism spectrum disorder. Med Hypotheses. 2014;83(6):718-25.

9. Jamnadass ES, Keelan JA, Hollier LP, Hickey M, Maybery MT, Whitehouse AJ. The perinatal androgen to estrogen ratio and autistic-like traits in the general population: a longitudinal pregnancy cohort study. J Neurodev Disord. 2015;7(1):17.

10. Phan A, Suschkov S, Molinaro L, Reynolds K, Lymer JM, Bailey CD, Kow LM, MacLusky NJ, Pfaff DW, Choleris E. Rapid increases in immature synapses parallel estrogen-induced hippocampal learning enhancements. Proc Natl Acad Sci U S A. 2015;112(52):16018-23.

11. Ervin KS, Lymer JM, Matta R, Clipperton-Allen AE, Kavaliers M, Choleris E. Estrogen involvement in social behavior in rodents: rapid and long-term actions. Horm Behav. 2015;74:53-76.

12. Chakrabarti B, Dudbridge F, Kent L, Wheelwright $\mathrm{S}$, Hill-Cawthorne G, Allison C, Banerjee-Basu S, Baron-Cohen S. Genes related to sex steroids, neural growth, and social-emotional behavior are associated with autistic traits, empathy, and Asperger syndrome. Autism Res. 2009;2(3):157-77.

13. Krezel W, Dupont S, Krust A, Chambon P, and Chapman PF. Increased anxiety and synaptic plasticity in estrogen receptor beta-deficient mice. Proc Natl Acad Sci U S A 2001;98(21):12278-82.

14. Crider A, Thakkar R, Ahmed AO, Pillai A. Dysregulation of estrogen receptor beta (ERbeta), aromatase (CYP19A1), and ER co-activators in the middle frontal gyrus of autism spectrum disorder subjects. Mol Autism. 2014;5(1):46.

15. Liu Z, Gou Y, Zhang H, Zuo H, Zhang H, Liu Z, Yao D. Estradiol improves cardiovascular function through up-regulation of SOD2 on vascular wall. Redox Biol. 2014;3(0):88-99.

16. Li H, Liu Z, Gou Y, Yu H, Siminelakis S, Wang S, Kong D, Zhou Y, Liu Z, Ding $Y$, et al. Estradiol mediates vasculoprotection via ERRa-dependent regulation of lipid and ROS metabolism in the endothelium. J Mol Cell Cardiol. 2015; 87:92-101.

17. Kong D, Zhan Y, Liu Z, Ding T, Li M, Yu H, Zhang L, Li H, Luo A, Zhang D, et al. SIRT1-mediated ER $\beta$ suppression in the endothelium contributes to vascular aging. Aging Cell. 2016;15:1092-1102.

18. Zhan Y, Liu Z, Li M, Ding T, Zhang L, Lu Q, Liu X, Zhang Z, Vlessidis A, Aw $T Y$, et al. ER $\beta$ expression in the endothelium ameliorates ischemia/ reperfusion-mediated oxidative burst and vascular injury. Free Radic Biol Med. 2016:96:223-33.

19. Simone J, Bogue EA, Bhatti DL, Day LE, Farr NA, Grossman AM, Holmes PV. Ethinyl estradiol and levonorgestrel alter cognition and anxiety in rats concurrent with a decrease in tyrosine hydroxylase expression in the locus coeruleus and brain-derived neurotrophic factor expression in the hippocampus. Psychoneuroendocrinology. 2015;(62):265-78.

20. Andrews P, Freyberger A, Hartmann E, Eiben R, Loof I, Schmidt $U$, Temerowski M, Folkerts A, Stahl B, Kayser M. Sensitive detection of the endocrine effects of the estrogen analogue ethinylestradiol using a modified enhanced subacute rat study protocol (OECD test guideline no. 407). Arch Toxicol. 2002;76(4):194-202.

21. Coelingh Bennink HJ, Skouby S, Bouchard P, Holinka CF. Ovulation inhibition by estetrol in an in vivo model. Contraception. 2008;77(3):186-90.

22. Kumar N, Koide SS, Tsong Y, Sundaram K. Nestorone: a progestin with a unique pharmacological profile. Steroids. 2000;65(10-11):629-36.

23. Genazzani AR, Gambacciani M, Simoncini T, Schneider HP, International Menopause S. "Controversial issues in climacteric medicine" series 3rd Pisa workshop "HRT in climacteric and aging brain". Pisa, Italy, 15-18 march 2003. Maturitas. 2003;46(1):7-26.

24. Hu M, Richard JE, Maliqueo M, Kokosar M, Fornes R, Benrick A, Jansson T, Ohlsson C, Wu X, Skibicka KP, et al. Maternal testosterone exposure increases anxiety-like behavior and impacts the limbic system in the offspring. Proc Natl Acad Sci U S A. 2015;112(46):14348-53.

25. Bahi A. Hippocampal BDNF overexpression or microR124a silencing reduces anxiety- and autism-like behaviors in rats. Behav Brain Res. 2017;326:281-90.

26. White SW, Oswald D, Ollendick T, Scahill L. Anxiety in children and adolescents with autism spectrum disorders. Clin Psychol Rev. 2009;29(3):216-29.
27. Bahi A. Sustained lentiviral-mediated overexpression of microRNA124a in the dentate gyrus exacerbates anxiety- and autism-like behaviors associated with neonatal isolation in rats. Behav Brain Res. 2016;311:298-308.

28. Hay CW, Shanley L, Davidson S, Cowie P, Lear M, McGuffin P, Riedel G, McEwan IJ, MacKenzie A. Functional effects of polymorphisms on glucocorticoid receptor modulation of human anxiogenic substance-P gene promoter activity in primary amygdala neurones. Psychoneuroendocrinology. 2014;47:43-55.

29. Yao D, Vlessidis AG, Gou Y, Zhou X, Zhou Y, Evmiridis NP. Chemiluminescence detection of superoxide anion release and superoxide dismutase activity: modulation effect of Pulsatilla chinensis. Anal Bioanal Chem. 2004;379(1):171-7.

30. Yao D, Shi W, Gou Y, Zhou X, Yee Aw T, Zhou Y, Liu Z. Fatty acid-mediated intracellular iron translocation: a synergistic mechanism of oxidative injury. Free Radic Biol Med. 2005;39(10):1385-98.

31. Ogino S, Kawasaki T, Brahmandam M, Cantor M, Kirkner GJ, Spiegelman D, Makrigiorgos GM, Weisenberger DJ, Laird PW, Loda M, et al. Precision and performance characteristics of bisulfite conversion and real-time PCR (MethyLight) for quantitative DNA methylation analysis. J Mol Diagn. 2006; 8(2):209-17

32. Eads CA, Danenberg KD, Kawakami K, Saltz LB, Blake C, Shibata D, Danenberg PV, Laird PW. MethyLight: a high-throughput assay to measure DNA methylation. Nucleic Acids Res. 2000;28(8):E32.

33. Nosho K, Irahara N, Shima K, Kure S, Kirkner GJ, Schernhammer ES, Hazra A, Hunter DJ, Quackenbush J, Spiegelman D, et al. Comprehensive biostatistical analysis of CpG island methylator phenotype in colorectal cancer using a large population-based sample. PLoS One. 2008;3(11):e3698.

34. Hagberg CE, Falkevall A, Wang X, Larsson E, Huusko J, Nilsson I, van Meeteren LA, Samen E, Lu L, Vanwildemeersch M, et al. Vascular endothelial growth factor B controls endothelial fatty acid uptake. Nature. 2010; 464(7290):917-21.

35. Taib B, Bouyakdan K, Hryhorczuk C, Rodaros D, Fulton S, Alquier T. Glucose regulates hypothalamic long-chain fatty acid metabolism via AMP-activated kinase (AMPK) in neurons and astrocytes. J Biol Chem. 2013;288(52):37216-29.

36. Huynh FK, Green MF, Koves TR, Hirschey MD. Measurement of fatty acid oxidation rates in animal tissues and cell lines. Methods Enzymol. 2014;542: 391-405.

37. Huang WC, Chen Y, Page DT. Hyperconnectivity of prefrontal cortex to amygdala projections in a mouse model of macrocephaly/autism syndrome. Nat Commun. 2016;7:13421.

38. Kleinhans NM, Reiter MA, Neuhaus E, Pauley G, Martin N, Dager S, Estes A. Subregional differences in intrinsic amygdala hyperconnectivity and hypoconnectivity in autism spectrum disorder. Autism Res. 2016;9(7):760-72.

39. Schumann CM, Hamstra J, Goodlin-Jones BL, Lotspeich LJ, Kwon H, Buonocore MH, Lammers CR, Reiss AL, Amaral DG. The amygdala is enlarged in children but not adolescents with autism; the hippocampus is enlarged at all ages. J Neurosci. 2004;24(28):6392-401.

40. Twining RC, Vantrease JE, Love S, Padival M, Rosenkranz JA. An intraamygdala circuit specifically regulates social fear learning. Nat Neurosci. 2017;20(3):459-69.

41. Rossignol DA, Frye RE. Evidence linking oxidative stress, mitochondrial dysfunction, and inflammation in the brain of individuals with autism. Front Physiol. 2014;5:150.

42. Clark-Taylor T, Clark-Taylor BE. Is autism a disorder of fatty acid metabolism? Possible dysfunction of mitochondrial beta-oxidation by long chain acylCoA dehydrogenase. Med Hypotheses. 2004;62(6):970-5.

43. Macfabe D. Autism: metabolism, mitochondria, and the microbiome. Glob Adv Health Med. 2013;2(6):52-66

44. Villafuerte S. Suggestive evidence on the genetic link between mitochondria dysfunction and autism. Acta Psychiatr Scand. 2011;123(2):95.

45. Epperson CN, Wisner KL, Yamamoto B. Gonadal steroids in the treatment of mood disorders. Psychosom Med. 1999;61(5):676-97.

46. Welling LL. Psychobehavioral effects of hormonal contraceptive use. Evol Psychol. 2013;11(3):718-42.

47. Bottcher B, Radenbach K, Wildt L, Hinney B. Hormonal contraception and depression: a survey of the present state of knowledge. Arch Gynecol Obstet. 2012;286(1):231-6.

48. Segebladh B, Borgstrom A, Odlind V, Bixo M, Sundstrom-Poromaa I. Prevalence of psychiatric disorders and premenstrual dysphoric symptoms in patients with experience of adverse mood during treatment with combined oral contraceptives. Contraception. 2009;79(1):50-5. 
49. Hall KS, White KO, Rickert VI, Reame N, Westhoff C. Influence of depressed mood and psychological stress symptoms on perceived oral contraceptive side effects and discontinuation in young minority women. Contraception. 2012:86(5):518-25.

50. Santoru F, Berretti R, Locci A, Porcu P, Concas A. Decreased allopregnanolone induced by hormonal contraceptives is associated with a reduction in social behavior and sexual motivation in female rats. Psychopharmacology. 2014;231(17):3351-64.

51. Auyeung B, Knickmeyer R, Ashwin E, Taylor K, Hackett G, Baron-Cohen S. Effects of fetal testosterone on visuospatial ability. Arch Sex Behav. 2012; 41(3):571-81.

52. Pfaff DW, Rapin I, Goldman S. Male predominance in autism: neuroendocrine influences on arousal and social anxiety. Autism Res. 2011; 4(3):163-76.

53. Mitra SW, Hoskin E, Yudkovitz J, Pear L, Wilkinson HA, Hayashi S, Pfaff DW, Ogawa S, Rohrer SP, Schaeffer JM, et al. Immunolocalization of estrogen receptor beta in the mouse brain: comparison with estrogen receptor alpha. Endocrinology. 2003;144(5):2055-67.

54. Wang L, Andersson S, Warner M, Gustafsson JA. Estrogen receptor (ER)beta knockout mice reveal a role for ERbeta in migration of cortical neurons in the developing brain. Proc Natl Acad Sci U S A. 2003;100(2):703-8.

55. Behl C. Oestrogen as a neuroprotective hormone. Nat Rev Neurosci. 2002; 3(6):433-42.

56. Hallmayer J, Cleveland S, Torres A, Phillips J, Cohen B, Torigoe T, Miller J, Fedele A, Collins J, Smith K, et al. Genetic heritability and shared environmental factors among twin pairs with autism. Arch Gen Psychiatry. 2011;68(11):1095-102.

57. Constantino JN, Zhang Y, Frazier T, Abbacchi AM, Law P. Sibling recurrence and the genetic epidemiology of autism. Am J Psychiatry. 2010;167(11): 1349-56.

58. Gardener H, Spiegelman D, Buka SL. Perinatal and neonatal risk factors for autism: a comprehensive meta-analysis. Pediatrics. 2011;128(2):344-55.

\section{Submit your next manuscript to BioMed Central and we will help you at every step:}

- We accept pre-submission inquiries

- Our selector tool helps you to find the most relevant journal

- We provide round the clock customer support

- Convenient online submission

- Thorough peer review

- Inclusion in PubMed and all major indexing services

- Maximum visibility for your research

Submit your manuscript at www.biomedcentral.com/submit

C) Biomed Central 